\title{
Experiencias
}

\section{Actuaciones emprendidas para atender a la población de alumnos con diversidad funcional visual de la bahía de Cádiz durante el confinamiento por covid-19}

\author{
Action taken in support of the community of students \\ with visual functional diversity in the Bay of Cádiz area \\ during the covid-19 lockdown
}

M. J. Gómez Paredes, C. Mateos Herrera

\section{Resumen}

En el trabajo que se presenta desarrollamos brevemente el apoyo realizado por el Equipo Específico de la Dirección de Zona (DZ) de la ONCE de Cádiz durante la situación de confinamiento por la pandemia generada por la covid-19. Exponemos nuestra visión del tipo de apoyo que debían recibir nuestro alumnado en estas condiciones tan especiales y extrañas, centrándonos, preferentemente, en el apoyo emocional. Así mismo, se dan a conocer los diversos tipos de actividades propuestas: individuales, en pequeño grupo, todo el grupo. Valoramos la necesidad de que los alumnos y sus familias se familiaricen y utilicen los medios tiflotecnológicos a su alcance, puesto que no sabemos si esta situación se puede volver a repetir, por lo que debemos estar preparados.

\section{Palabras clave}

Confinamiento. Tiflotecnología. Apoyo educativo. Apoyo emocional.

\begin{abstract}
The article briefly describes the support provided by the ONCE Zone Division's Team for the Specific Support of Students with Visual Disability working out of Cádiz during the lockdown


called in the wake of the covid-19 pandemic. It sets out the authors' beliefs around the type of assistance students should receive in such unusual circumstances, with a focus on emotional support. Proposals for activities targeting individuals, small groups or whole classrooms are also addressed. A need is identified for students and their families to acquire competent use of the aids and appliances available to successfully rise to possible future challenges of a similar nature, for which all concerned must be prepared.

\section{Key words}

Lockdown. Aids and appliances for visually impaired persons. Educational support. Emotional support.

\section{Introducción}

Como a todos los profesionales del mundo de la educación, el confinamiento por la pandemia, nos cogió por sorpresa. De un día para otro tuvimos que cambiar nuestro tradicional trabajo «itinerante», por el mismo, pero «sedentario».

Una de las primeras dudas que tuvimos al iniciarse el confinamiento y plantearnos continuar el apoyo fue: ¿educativo, académico? ¿Eso era lo más importante en estos momentos?

Los alumnos tenían montones de tareas que les mandaban en los colegios o institutos, ¿qué más les íbamos a encargar nosotros? Evidentemente, teníamos claro que cualquier adaptación o necesidad que tuvieran en ese ámbito, la íbamos a resolver, ya fuera sobre braille, intervención de la Instructora tiflotécnica, organización en casa...

Sabíamos con certeza que la situación les iba a afectar en otros aspectos, sobre todo en el emocional, así que nos pusimos manos a la obra e intentamos hacer un programa de intervención que se ocupara del ocio, de la relación con sus iguales, del control e identificación de sus emociones, de las actividades con la familia, etc.

El primer paso fue organizar una agenda de trabajo entre los profesionales que no estaban en situación de regulación temporal de empleo: maestros, profesores, Instructora tiflotécnica, psicólogo. 
«Listo; dos días a la semana nos vemos por Skype y planteamos las actividades que tenemos que preparar para la siguiente».

La idea fue crear actividades individuales (boletines, cuento nocturno), con la familia (recetas de cocina), en pequeño grupo (retos wasaperos, quedadas por Skype para ver una película, charlar...), para todo el grupo (Noticiario, Minipatrulla ONCE, cuento colaborativo para el día del libro...).

Es cierto que el grueso de las actividades se dirigió a alumnos de infantil y primaria, aunque en algunas de ellas participaron otros de secundaria.

\section{Tipos de actividades}

1. Boletín de actividades. Cada semana realizamos dos boletines de actividades de diferentes temas: manualidades, recetas de cocina, juegos, ciencia, emociones (ver Figura 1). Se le enviaba un boletín vía WhatsApp para llevar a cabo solos o junto con algunos miembros de su familia. En total, se han realizado 26 boletines.

Figura 1. Ejemplo de boletín. Según la temática del mismo, la cabecera es de un color diferente

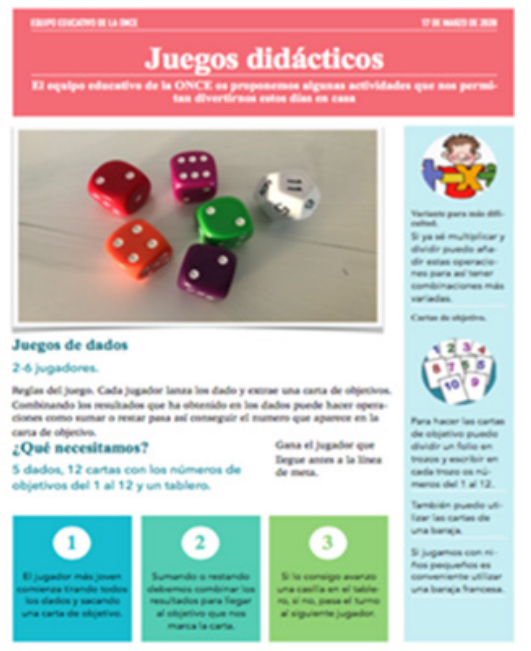

2. «Déjame que te cuente...». Una de las maestras seleccionaba un cuento de Eloy Moreno, lo grababa y lo enviaba a las familias por WhatsApp cada tarde.

Gómez, M. J., y Mateos, C. (2021). Actuaciones emprendidas para atender a la población de alumnos con diversidad funcional visual de la bahía de Cádiz durante el confinamiento por covid-19. RED Visual: Revista Especializada en Discapacidad Visual, 77, 278-283. https://doi.org/10.53094/WKHU5747. 
Figura 2. Ilustración infantil realizada para identificar la actividad

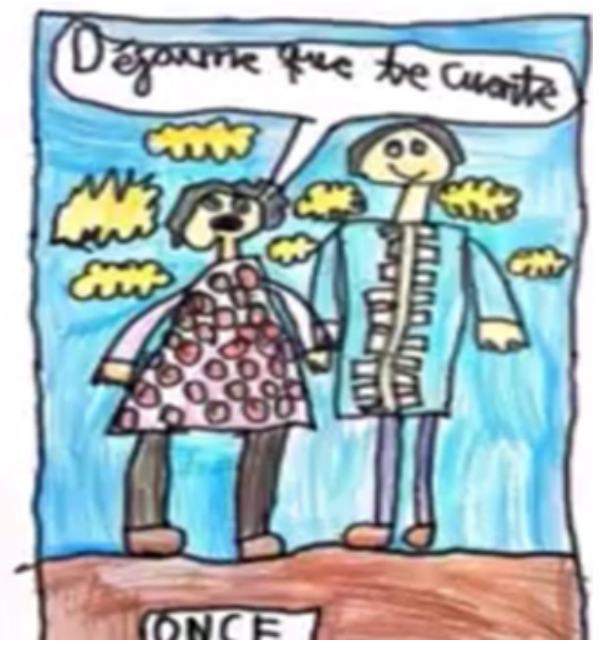

3. Retos «wasaperos». Por grupos de alumnos, se le proponía un reto a uno de ellos; por ejemplo, decir una adivinanza, y los demás debían encontrar la respuesta a dicha adivinanza, contar un chiste que los demás debían puntuar según la gracia que les hiciera...

4. Cuento colaborativo. Con motivo del Día Internacional del Libro realizamos un cuento improvisado, todos estaban conectados y podían escuchar las aportaciones de los compañeros. Se creó una cadena y cada alumno debía continuar la historia donde la dejaba el compañero. Al finalizar, se realizó un vídeo con sus locuciones y los dibujos realizados por ellos mismos.

Figura 3. Cartel animando a los alumnos a que participen en la actividad del Día Internacional del Libro

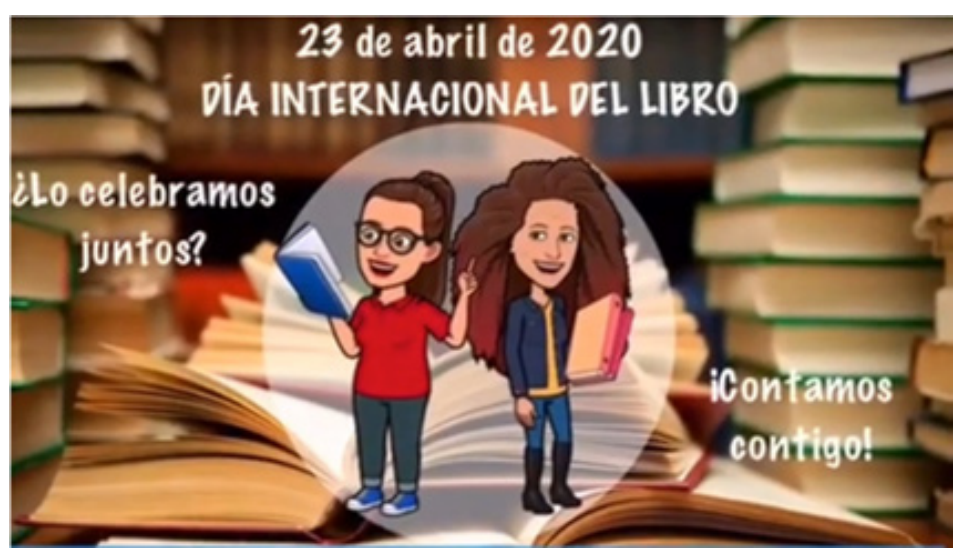

Gómez, M.J., y Mateos, C. (2021). Actuaciones emprendidas para atender a la población de alumnos con diversidad funcional visual de la bahía de Cádiz durante el confinamiento por covid-19. RED Visual: Revista Especializada en Discapacidad Visual, 77, 278-283. https://doi.org/10.53094/WKHU5747. 
5. Minipatrulla ONCE contra el coronavirus. Con los alumnos se realizó un pequeño vídeo en el que estos, disfrazados, luchaban con sus propias herramientas contra el coronavirus, finalizando con las orientaciones para preservarse del virus.

6. 11 noticias de Cádiz. Para finalizar las actividades, realizamos un «videonoticiero» en el que cada alumno elaboraba una noticia sobre un tema: deportes, actualidad, tecnología, ocio, el tiempo... La grababa en vídeo y se montaba en grupo.

Figura 4. Logotipo de la cabecera del programa 11 noticias de Cádiz

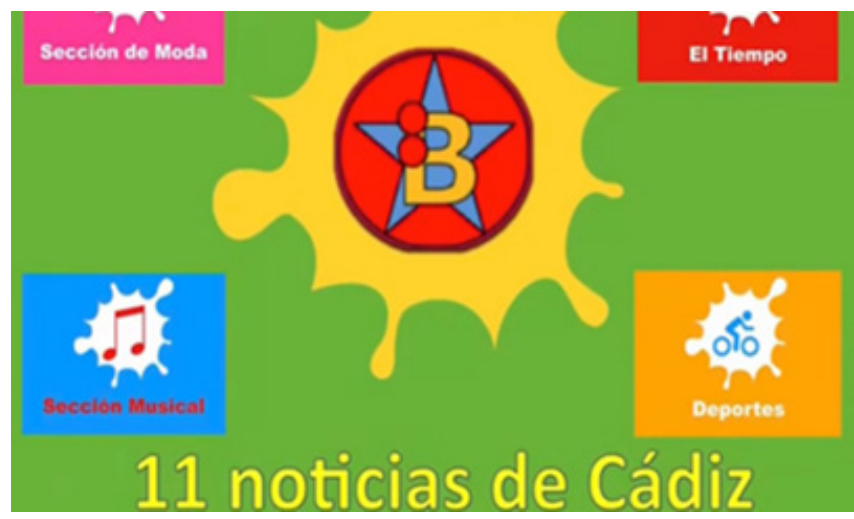

7. Canal de YouTube. Se creó un canal de YouTube en el que se han ido colgando las actividades realizadas, videorrecetas, orientaciones para adaptar cuentos, videonoticiero... ${ }^{1}$

\section{Resultados}

Básicamente, con todo lo planteado y, sobre todo, teniendo en cuenta la participación de los alumnos en todas las actividades, así como las opiniones de los mismos y de sus familias, creemos que se ha conseguido:

- Que los alumnos se conocieran entre ellos y que los que ya se conocían no perdieran el contacto, ya que no podían ir a las actividades organizadas por el Centro de Recursos Educativos de la ONCE en Sevilla.

1 La URL del citado canal es https://youtube.com/channel/UC2wRw6YDyqLEsNOKDgv-rqw. 
- Que los alumnos no se sintieran aislados en casa.

- Que los alumnos y las familias supieran que su equipo de apoyo está ahí.

- Que los alumnos utilizaran las nuevas tecnologías, o se iniciaran en ellas, y les encontraran la utilidad.

- Que su nivel de ansiedad se redujera.

- Que los medios de comunicación se hicieran eco de muchas de las actividades realizadas (se ha entrevistado a alumnos y a profesionales en prensa y radio).

Para finalizar, nos gustaría decir que, durante estos tiempos tan difíciles que a todos nos ha tocado vivir, hemos tratado de adaptarnos y reinventarnos para nunca perder nuestra esencia, esa que nos caracteriza: la cercanía, con nuestros alumnos y sus familias. Hemos sido cocineros, periodistas, escritores, dibujantes, locutores de historias y más historias, pero, lo más importante, hemos sido «familia», «cercanos», hemos sido «apoyo» ante los momentos más difíciles y «respiro» cuando nos agobiaban las tareas. Hemos sido, como no podía ser de otra manera, maestros, pero no solo de los alumnos, también de sus familias, puesto que ellos han tenido que aprender nuestro trabajo para poder ayudar a sus hijos en sus adaptaciones ante la imposibilidad de vernos, desplazarnos y facilitarles los materiales adaptados.

Esperemos que no tengamos que llegar a situaciones tan extremas, pero, en el caso de que ocurriese, «Estamos preparados».

María Jesús Gómez Paredes. Maestra del Equipo específico de atención educativa de la ONCE en Cádiz. Agencia de Chiclana. Nuestra Señora de los Remedios, 8; 11130 Chiclana, Cádiz (España). Correo electrónico: mgpa@once.es.

Cristina Mateos Herrera. Maestra del Equipo Específico de Atención Educativa de la ONCE en Cádiz. Acacias, 5; 11007 Cádiz (España). Correo electrónico: crmh@once.es. 